\title{
Effectiveness of Gamification Activities in a Project-based Learning Class- room
}

\section{Dr. Eleanor Leung, Minnesota State University Mankato, Iron Range Engineering}

Dr. Eleanor Leung is an assistant professor with the Iron Range Engineering (IRE) program which is part of Minnesota State University, Mankato. She joined IRE in August 2016 and is the electrical engineering faculty member who leads competencies in the areas of electric machines, signals and systems, three phase systems and controls systems. Her research area is in wireless communications focusing on space-time block coding and the design of signal constellations. She has a B.S in Electrical Engineering from the University of Calgary and both a M.Eng and a Ph.D in Electrical Engineering from McMaster University.

\section{Dr. Elizabeth Pluskwik, Minnesota State University, Mankato / Iron Range Engineering}

Elizabeth leads the Engineering Management and Statistics competencies at Iron Range Engineering, an ABET-accredited project-based engineering education program in Minnesota. She enjoys helping student engineers develop entrepreneurial mindsets through active and collaborative learning in the classroom, on project design teams, and while out on co-op work. Her prior education and work experience were in business and accounting, and her Ph.D. in Organization and Management is from Capella University, Minneapolis. She recently gained Six Sigma and Lean certifications. Elizabeth and her husband have a photography business and spend time outdoors with their cameras photographing community events, people, and places in the natural beauty of northern Minnesota. 


\title{
Effectiveness of Gamification Activities in a Project-Based Learning Classroom
}

\begin{abstract}
The purpose of this research is to analyze the effectiveness, and student's self-reported engagement with gamification tools on a student's learning of technical concepts when used in a project-based learning (PBL) engineering classroom environment. Gamification, as defined in this study, is the use of game-based elements such as online audience response systems with automated feedback in non-game situations. By adding gamification to the classroom, we hope to further build on the active and collaborative learning environment that our PBL program already provides. Five gamification activities were implemented during the Fall 2017 semester with junior and senior student engineers enrolled in Iron Range Engineering, a program of Minnesota State University, Mankato. The Iron Range Engineering (IRE) model is a project-based-learning program in which students work closely with industry on design projects throughout their 3rd and 4th years. The goal of this program's approach is to prepare and produce graduates with significant integrated technical and professional knowledge and skills to enter the engineering workforce. The three game-based online platforms along with two hands-on activities were used in six technical courses: Signals \& Systems, Engineering Economics, Statistics, Linear Control Systems, Lean Principles, and Electric Machines. All five gamification tools allowed for real-time assessment, so students were given instant feedback from the game on their level of understanding of a technical concept. The in-class gaming activities were used in approximately five instances within the six courses; with about 8 - 12 participants in each class ( $\mathrm{n}$ is approx 300 student gaming interaction instances). Feedback was collected via student surveys, student and faculty reflections and data received automatically by the game programs. Preliminary analysis of student feedback and faculty reflections indicates increased learner motivation, enhanced review of technical content and an upbeat atmosphere to the classroom. Faculty reflections also noted that the use of games that allow learners to answer the questions individually helped faculty identify those students who had successfully mastered the concepts, which allowed the instructor to structure peer-to-peer active learning opportunities during class more effectively. Future work includes analyzing test scores, and other measures of long-term retention of concepts. Overall, use of these gamification tools was found to be a significant addition to the project-based learning environment at Iron Range Engineering, bringing value to the overall learning process and will continue to be used to improve our teaching and student learning.
\end{abstract}




\section{Introduction}

Traditional teaching methods are often unengaging for certain types of students. In recent years, the use of active learning strategies has been on the rise. Current research suggests that these strategies can lead to improvements in learner engagement, problem-solving skills, and long-term retention of knowledge. One technique of active learning is gamification, which is a challenge activity defined by rules, where players interact with each other or the gaming platform, to provoke an emotional reaction and finally, result in a quantifiable outcome [1]. Also, learning may occur. The games in this paper include three online gaming tools and two other physical, hands-on games that can be played in engineering education classrooms. These tools are easily integrated into classroom sessions for introducing new concepts, deliberate practice, kinesthetically experiencing abstract concepts and facilitating peer to peer discussion around challenging topics.

\section{Theoretical Foundation and Related Work}

Gamification is described as activities that use game-like or "fun" elements to promote learning and engagement [1]. The nine elements of a game, per Kapp [1] are:

1. System - a set of interconnected elements in the "space" of the game. Scores linked to actions, and actions limited by rules.

2. Players - a person interacts with game content or with other players. In education, the players are learners, who will learn from playing the game.

3. Abstract - the game contains some elements of a realistic situation but is not a replica; it is somewhat abstract.

4. Challenge - games challenge players to overcome barriers and achieve goals and outcomes that are not easy. The element of challenge leads to motivation to persist and complete the task.

5. Rules - rules define a game. They are the structure that is needed to set boundaries, keep score, identify what is fair and allowed.

6. Interactivity - players of a game must interact with one another, with the game system, and with the content of the game.

7. Feedback - an essential part of games is the feedback they provide to the player; it is usually instant, direct, and clear.

8. Quantifiable outcome - the winning state or situation must be clear. A player achieving a winning state signifies the end of the game; this is different from the playing state, which has no quantifiable end state or outcome. Players know when they win.

9. Emotional reaction - this is the full range of emotions that comes from playing, winning, and losing a game. Games can evoke strong emotions. 
A full description of these elements with examples can be found in "The Gamification of Learning and Instruction," book by Karl Kapp [1].

Structural gamification [2] is the application of game elements to motivate learners to go through the content and to engage them in the process of learning through rewards. The most common form of this type of gamification are points, badges, achievements, and levels and only one of these elements of a game are needed to engage a person. It also encourages the learner to return to the material on a regular basis.

For gamification to truly impact participant learning in positive ways, the integration of game-inspired elements must go beyond superficial combinations like points or badges to focus on more in-depth structural considerations of games such as the story, the challenge, the sense of control, decision making, and a sense of mastery [1]. Gaming often promotes authentic learning and ample problem-solving opportunities. When playing games, individuals are likely to become immersed in the experience and, as a result of this engagement, are more likely to remember information and develop an enduring understanding of concepts [3]. Games also offload mistakes to the process of play in a way that minimizes personal association with failure and encourages students to strive for mastery [4].

Other recent work on gamification in teaching and learning describes it as a social and democratic way to promote innovation and creativity. It is an alternative process "to think our way out of problems" or promote "fluid creativity" [5]. Gabe Zichermann suggests that "feedback, friends, and fun" are the required elements in an engaging game to achieve social learning in a game-based environment. In his TEDx talk from Feb. 2014, Zichermann says, "If we want to take advantage of the power of games, we need to collectively decide to actively put the power of games to work, to inspire creativity and innovation." [5]

There are many examples of using gamification being currently used in engineering classes to benefit student learning from individual student response systems [6, 7] to gamifying a learning management system for a virtual learning environment $[8,9]$. The authors decided to use multiple different online and physical gamified activities throughout the Fall 2017 semester in their engineering courses and observe the effectiveness of the student learning.

\section{Active Learning in Program Context}

The Iron Range Engineering (IRE) program is an upper-level undergraduate engineering education program located in northern Minnesota. As of January 2018, 125 students have graduated from the program. It is ABET accredited. The program began in 2010 and is modeled after the project-based learning (PBL) engineering program at Aalborg University in Denmark [10]. Project-based learning is a form of active learning where large-scale projects provide context for technical learning. Junior and senior student engineers at IRE work together in teams of 3 - 5 people with industry clients on semester-long projects. Each team has a project room or office where students work, collaborate, and study. The design project provides the opportunity to learn and apply engineering concepts which are further supported by classroom instruction. This structure is similar to senior design or a capstone project, but our program allows students to have a different industry project each semester of their junior and senior year. 
The program emphasizes continuous improvement and the development of self-regulated learning abilities, professional skills, and technical engineering knowledge, which is acquired primarily in one-credit courses called "competencies" [11]. Students learn in small groups (3 - 12 people) with academic staff facilitating the "learning conversations." These class meetings include some lecture but are primarily conversations between faculty and learners. Many learning conversations are flipped, so students learn the material outside of class meeting time. The in-class time is then used to ask questions, discuss with peers, apply the new knowledge to their industry projects, and use other active and collaborative learning techniques to make the newly acquired knowledge "sticky," so it is long-lasting and retrievable in the future. Simple active learning strategies such as think-pair-share, muddiest point, and minute papers are often used, as well as are more complex active learning techniques such as problem-based learning.

\section{Gamification Approaches in the Classroom}

To further enhance the active and collaborative learning environment, the use of game-based elements in non-gaming environments was adopted at Iron Range Engineering in the Fall, 2017. Three different game-based interactive online platforms of Plickers, Quizlet and Kahoot $[12,13,14]$ and two physical games of Immediate Feedback Assessment Technique (IF-AT) [15] and a modified Escape Room were used in the competencies of Signals \& Systems, Engineering Economics, Statistics, Lean Principles, Linear Control Systems and Electric Machines. Students were able to use interleaved spaced retrieval for review and retention of concepts as the games were played in a low-stakes environment to practice a student's understanding of technical concepts. The gaming platforms provided real-time assessment which allowed for instant feedback on students' level of technical knowledge. These are highly interactive learning activities between the students and faculty. A description of each of the five games follows.

Plickers [12] is a free online quizzing tool used by instructors to collect real-time assessment data without the use of any student devices. Students are each given a paper clicker card (plicker) which has a unique symbol, similar to a QR code on it. Each Plicker card also has a unique number that is assigned to individual students. The game questions appear on a large shared screen and students will hold their cards with their answer (A, B, C, or D) upright at the top of the card. Using the Plickers mobile app on the instructor's phone, it will automatically scan the answers in real-time and different colors will appear on the phone screen indicating if the student answered correctly or not, as shown in Figure 1. The tool records the real-time data to show how each student responded and their final cumulative score over a range of dates of the instructor's choosing. The instructor creates their own set of questions using the Plickers website and images can be embedded, but the answers are limited to two to four choices. This tool was used three to five instances in each of the courses of Signals \& Systems, Electric Machines, and Linear Control Systems.

Quizlet [14] is an online application that allows students to study and learn the terminology required for a course interactively. It is free for all students to use and is accessible on any mobile platform such as a smartphone, tablet, and laptop. A student or instructor can either make their own flashcards or search for preexisting sets for a particular topic. In addition to the flashcards 


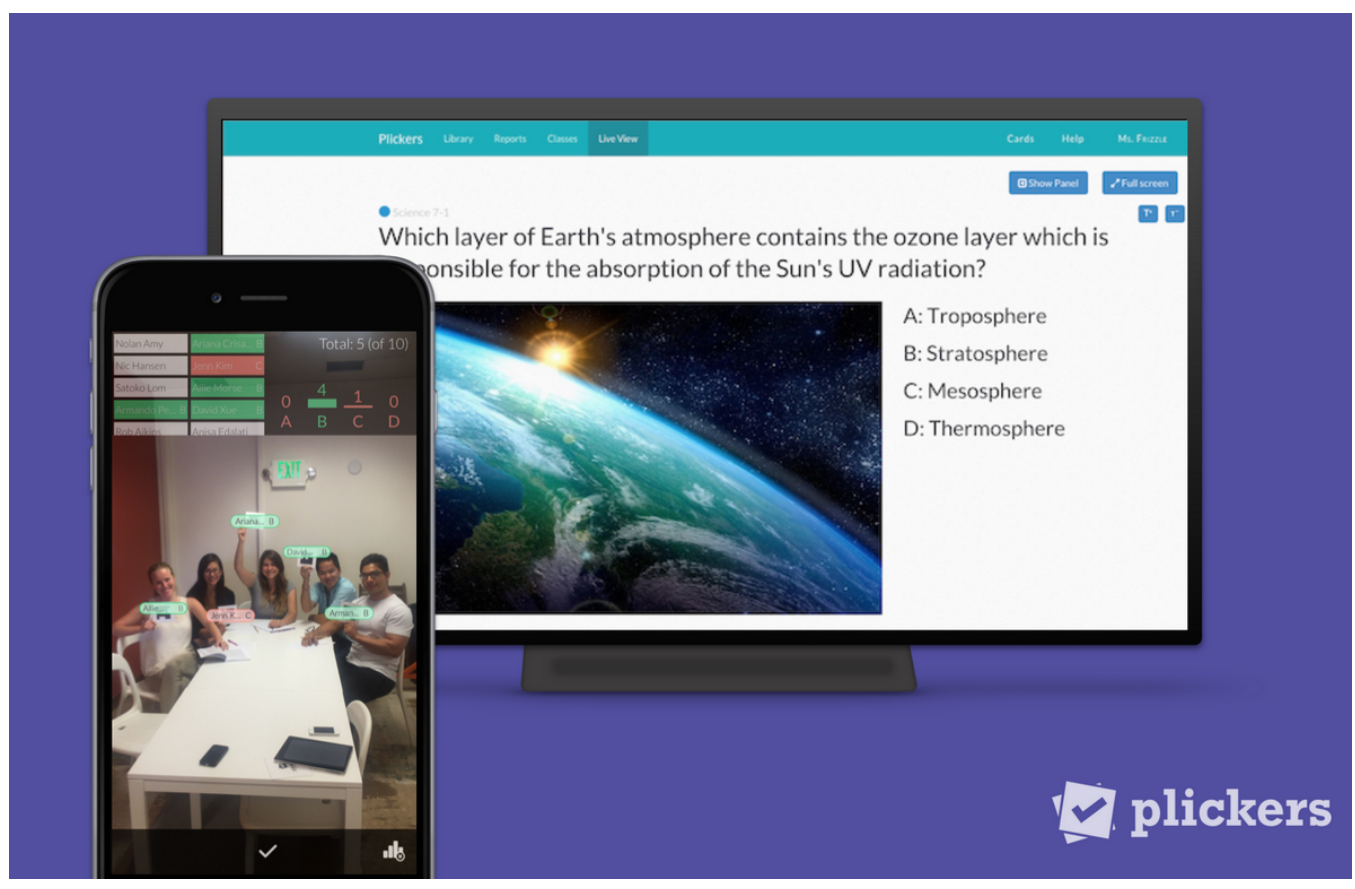

Figure 1: Plickers

feature there is also a test, games (match, gravity) section as shown in Figure 2. This tool was used once in each of the Signals \& Systems and Linear Control Systems courses.

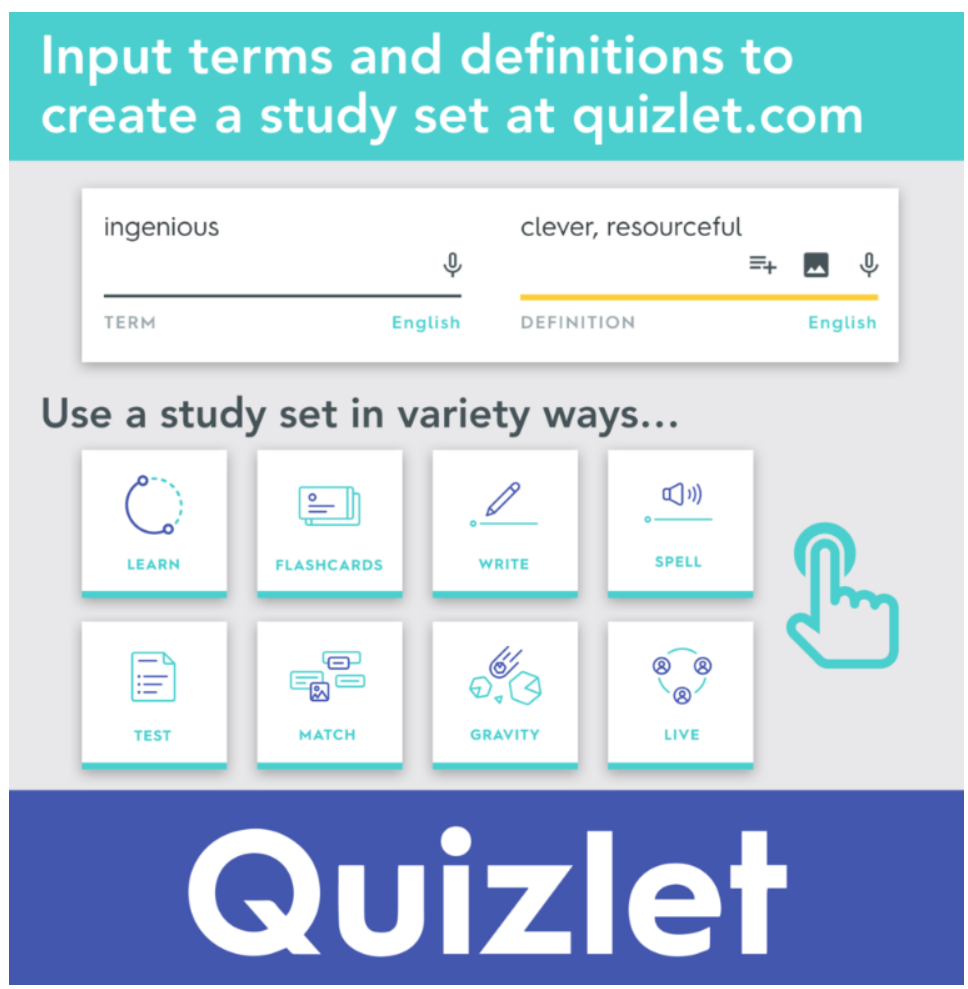

Figure 2: Quizlet 
Kahoot [13] is a free game-based learning platform in which the instructor creates questions on the website, or searches for preexisting game sets, that can be adapted by the instructor as well. Students play using their own devices such as a smartphone or laptop, as shown in Figure 3 . The game questions appear on a large shared screen and students answer via their device by selecting the colored shape that matches their answer choice, as shown on the shared screen. The challenges are colorful, fast-paced, and accompanied by lively music. Students earn points by answering the timed questions correctly and quickly on their devices. They can play individually or in teams and can use creative nicknames to add to the fun. Social learning occurs when students freely and openly discuss their answer choices, whether they got the question right or not, creating a "campfire moment" when the correct answer is revealed. It's a noisy game, generally, and well enjoyed by students, as their points increase on the scoreboard. Kahoot reinforces learning in a social and motivating environment. It was used twice in Statistics and once in each of the other competencies of Lean Principles, Electric Machines, Signals \& Systems, and Linear Control Systems. One of the co-authors also uses it regularly in a business course that she teaches.

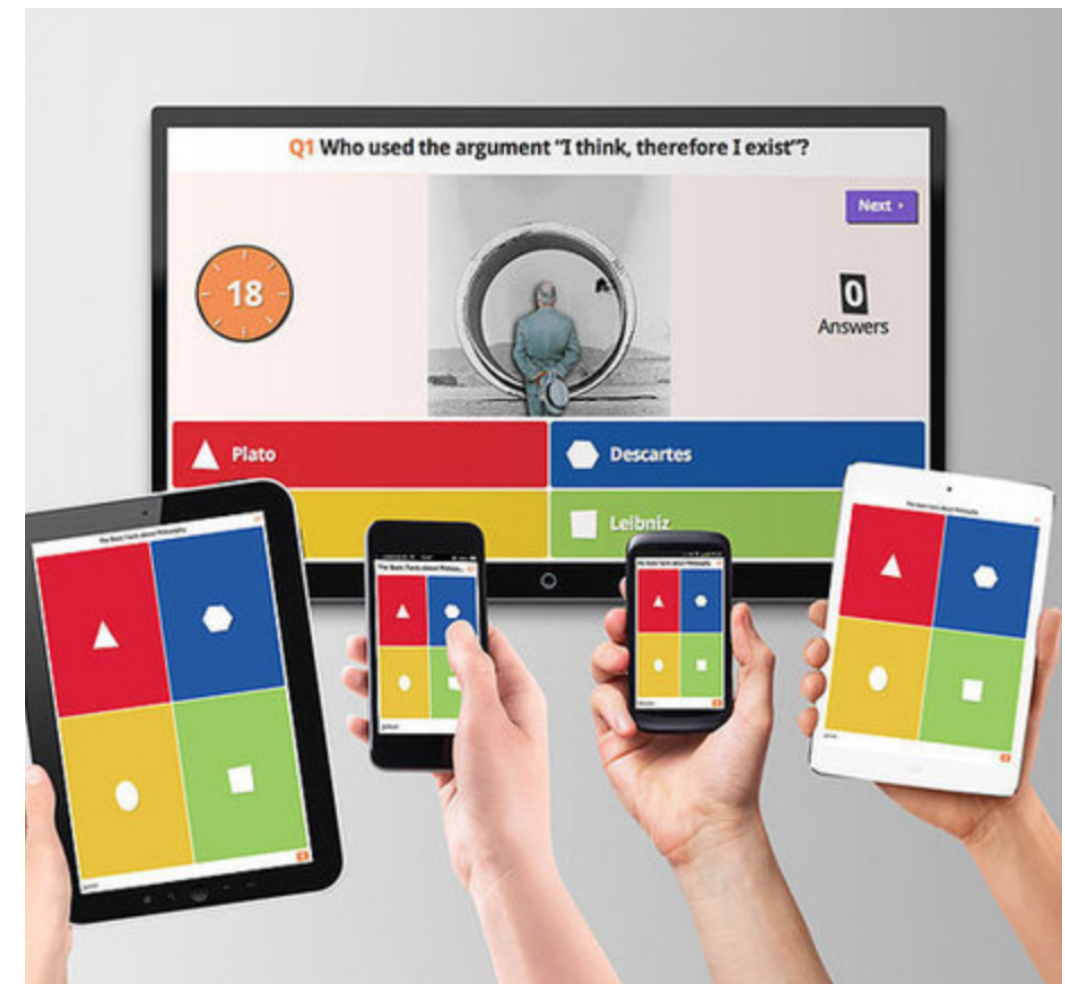

Figure 3: Kahoot

A physical way to gamify multiple choice quizzes and homework is the Immediate Feedback Assessment Technique (IF-AT scratch cards), available through Epstein Educational Enterprises [15]. This method uses scratch-off cards similar to lottery tickets. Rather than using a pencil to fill in the selected answer choice to a multiple choice question, the learner scratches off the coating of the IF-AT card corresponding to the selected answer choice. If a star is revealed under the coating, the student receives immediate feedback that they got the question right. If no star appears, the student re-thinks, scratches off another answer choice and continues until the star is revealed. Partial credit is given for the number of attempts at the correct answer via the scoring 
system. The cards contain an area for scorekeeping, in which students write in the number of unscratched off boxes for each question. These are totaled and the highest score wins. One of the benefits of the IF-AT cards is that students never leave a question without knowing the correct answer, which is psychologically crucial in learning [15]. The IF-AT cards are low-cost, mainly when purchased in bulk. From a faculty preparation standpoint, the multiple choice answer options must be arranged for each question such that the correct answer matches the pre-printed IF-AT card. Various versions of the card are available for purchase from Epstein Educational Enterprises. This game format was used once in a seminar with approximately 50 students, as well as in the Lean Principles course.

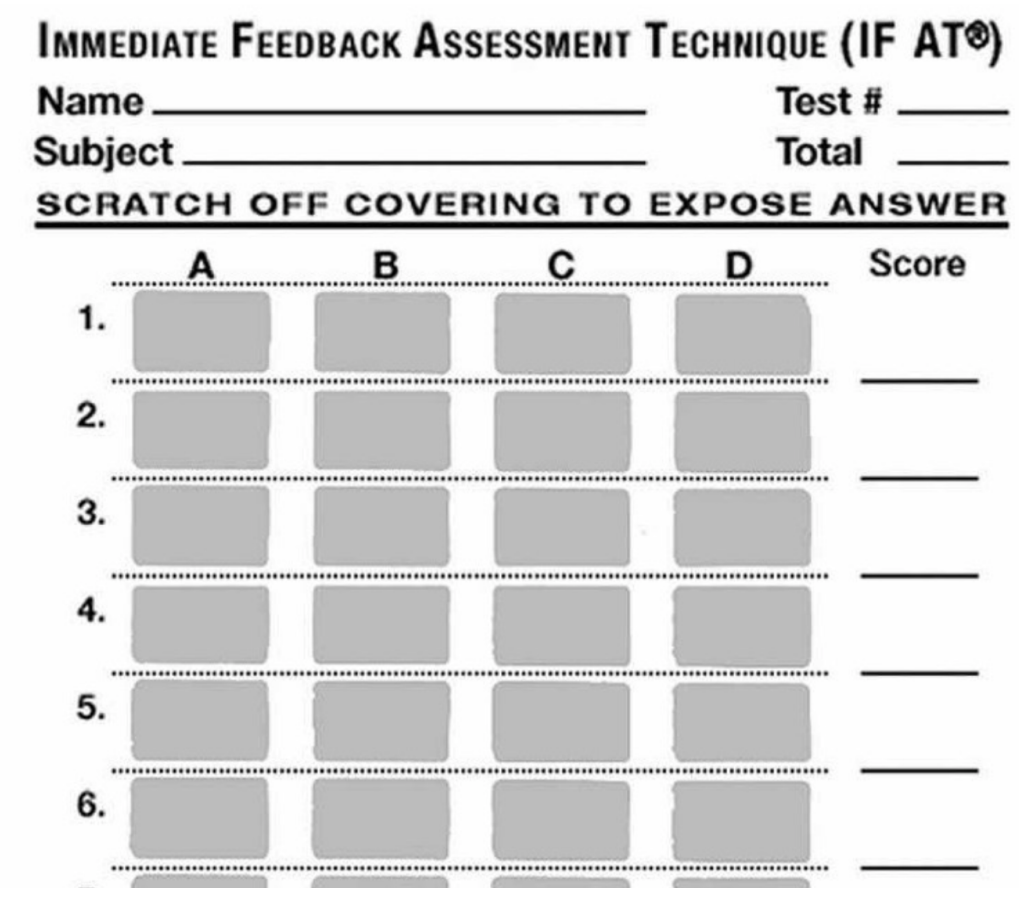

Figure 4: Immediate Feedback Assessment Technique (IF-AT) cards

Escape rooms are a physical adventure game to challenge players, where they must solve a series of puzzles to escape the room in a given time limit. Using this concept and also the active learning strategy of the gallery walk [16] we developed an escape room to help students practice their engineering fundamental principles. Different fundamental principles from a variety of core electrical, mechanical and business courses were listed on whiteboards around the room. After students individually make a paper origami dice, each student picked a principle they want to "master." They roll the dice at that principle's whiteboard. The number the dice lands on is that aspect of the principle the student needs to solve by writing out their answer on the whiteboard below the principle. For example, if a student rolls a 3 they must write the relevant formulas including units for that principle, whereas if they roll a 5 they will write an everyday application that utilizes the principle. Once they think they have the correct answer, they will raise their hand, and an instructor will come by and assess. If the answer is correct, the student gets a token, and they have "mastered" concept so move to master other concepts. If the answer is not correct, the student gets one more attempt at the same principle. To "escape the room," a student must acquire a certain number of tokens in each area of electrical, mechanical and business. This activity, 
which was an hour and a half, was held near the end of the semester with 18 upper division students participating. Instructions on how to make the origami dice were posted around the initial "briefing room." Then students went to the gymnasium where we setup up whiteboards spread out across the room as seen in Figure 5. Three faculty members, who are each a subject matter expert in mechanical, electrical or business engineering, provided minimal feedback in the form of "yes" or "no" to assess the students" answers.

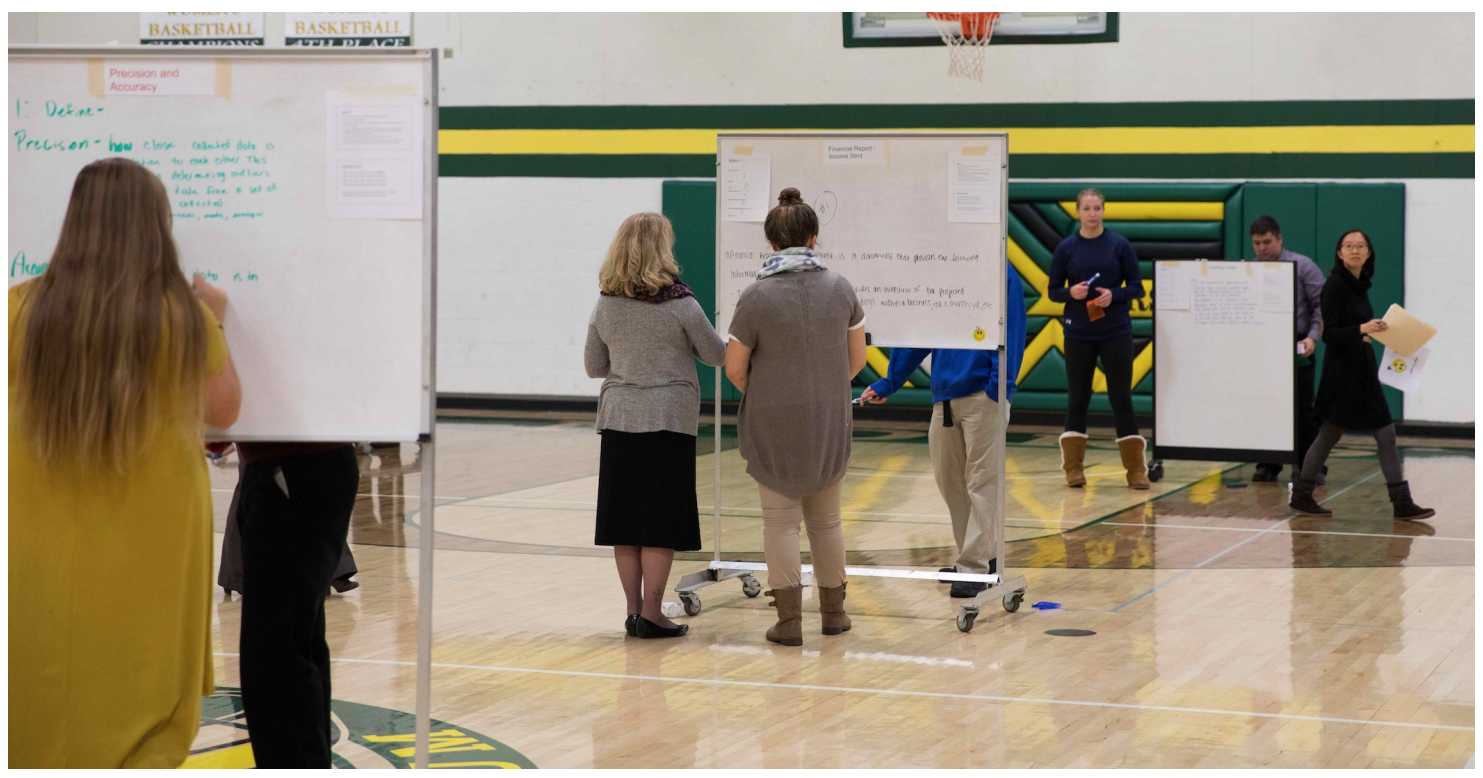

Figure 5: Escape Room Layout

\section{Numeric Metrics and Student Feedback}

During each competency, students were asked to write 2-3 reflections on how useful the gamification tools were towards their learning. They also completed paper and pencil surveys, which included questions on enjoyment, engagement, and value of the games played. An end of the semester, students completed an anonymous course evaluation focused on the specifics of gamification tools. Limited data was collected because our program has less than 50 students in upper division, so the sample size is automatically small. We plan to track the use of these games longitudinally in order to reach meaningful conclusions. The summarized data is displayed and discussed below.

All three online games were enjoyed by the students, as shown in Table 1. Kahoot received the highest "Enjoyment" rating, with 4.85 as the average. The Escape Room was less enjoyed, with a 3.96 average rating. "Engagement" levels also reported high, as shown in Table 2. Students found all three online games to be very engaging or close to that level, with average scores ranging from 4.5 to 5 for the three online games. Although sample sizes were small, the self-reported data correlates with faculty perceptions. A recurring student comment, independent of the class and gamification activity used, was these activities were fun and competitive. Below are some student comments on the online gamification tools. 


\section{Table 1: Student Self-Reported Enjoyment Level}

\begin{tabular}{c|c|c|c|c} 
Game & $\begin{array}{c}1 \text { (Did not } \\
\text { love it) }\end{array}$ & 3 & 5 (Loved it!) & $\begin{array}{c}\text { Average Rating (on } \\
1-5 \text { scale) }\end{array}$ \\
\hline Kahoot $(\mathrm{n}=10)$ & $0 \%$ & $10 \%$ & $90 \%$ & 4.85 \\
\hline Plickers $(\mathrm{n}=26)$ & $0 \%$ & $54 \%$ & $46 \%$ & 4.3 \\
\hline Quizlet $(\mathrm{n}=8)$ & $\begin{array}{c}\text { See student } \\
\text { comments }\end{array}$ & \multicolumn{3}{|l}{} \\
\hline Escape Room $(\mathrm{n}=13)$ & $8 \%$ & $69 \%$ & $23 \%$ & 3.96 \\
\hline
\end{tabular}

Table 2: Student Self-Reported Engagement Level

\begin{tabular}{c|c|c|c|c} 
Game & $\begin{array}{c}1(\text { Not } \\
\text { Engaged) }\end{array}$ & 3 & $\begin{array}{c}5 \text { (Very } \\
\text { Engaged) }\end{array}$ & $\begin{array}{c}\text { Average Rating (on } \\
1-5 \text { scale) }\end{array}$ \\
\hline Kahoot $(\mathrm{n}=10)$ & $0 \%$ & $0 \%$ & $100 \%$ & 5 \\
\hline Plickers $(\mathrm{n}=26)$ & $0 \%$ & $42 \%$ & $58 \%$ & 4.5 \\
\hline Quizlet $(\mathrm{n}=8)$ & $0 \%$ & $13 \%$ & $88 \%$ & 4.75 \\
\hline Escape Room $(\mathrm{n}=13)$ & $\begin{array}{c}\text { See student } \\
\text { comments }\end{array}$ & \multicolumn{4}{|l}{} \\
\hline
\end{tabular}

Student comments on the Kahoot survey include:

- "Boosted morale - made it fun."

- "Awesome way to study before exams."

- "Extremely engaged."

- "Exciting game with in-depth test on knowledge"

- "Reminded me of principles I don't know yet."

- "100\% positive experience."

- "It helps to think on your feet along with another person."

Student comments on Plickers survey include:

- "Kept the whole class engaged, and is a good review of the material."

- "It actually makes me want to understand the subject matter."

- "Performing transformations was much easier because of the quiz practice" from a Signals \& Systems student.

- "I do not like the fact that other people can see my answer. I'm more likely to work hard to understand it so I don't look like a fool next time."

- "Very beneficial. Motivating. Allowed us to quiz our knowledge in a memorable way."

- "Helps you think quickly on your feet, and makes you have to focus hard for those couple of minutes. Really gets you engaged in whats going on in the class." 
- "It is fun to start the class like that. There were similar answers with subtle differences and picking out those differences are a key to pick up on."

- "We got a chance to get immediate feedback on our conceptual learning to clean up anything misunderstood . It was very valuable."

- "There was a high learning value because of the retention it will create for me in the future. It was all relevant to our learning."

- "It adds fun to a class that could be stressful, also is another learning tool that uses adrenaline to remember items/concepts."

Student comments on the Quizlet survey include:

- "Allowed me to practice interleaved spaced retrieval."

- "I was enjoying it so I used it longer."

- "Allowed me to better connect terms and definitions."

- "I learn by listening and the flash cards have an option to read it to you, so that helped make it stickier."

For the Escape Room activity, additional feedback was collected to assess if this activity was beneficial to a student's learning of engineering fundamental principles. The Escape Room survey asked about the learning value of the escape room, whether it was more or less valuable than other learning methods, and students' rating of the minimal feedback method used by the three faculty assessors. The results are summarized in Table 3. Pre and post-level confidence levels were also noted by the "check-in" faculty member, who asked each student how confident they were in describing the fundamental principles of engineering, both before and immediately after the Escape Room activity. Figure 6 displays these results. Second-semester juniors reported the most significant change in confidence in their ability to describe the fundamental principles, with average reported levels increasing by 1.08 on a 5-point scale. First semester juniors and first semester seniors had virtually no change, and second-semester seniors reported a small increase of .13 on a 5-point scale. Overall, $44 \%$ of students self-reported higher levels of confidence after the Escape Room activity.

Table 3: Student Self-Reported Feedback for Escape Room Activity (n=13)

\begin{tabular}{c|c|c|c|c} 
Question & 1 (Low) & 3 (Medium) & 5 (High) & $\begin{array}{c}\text { Average Rating (on } \\
1-5 \text { scale) }\end{array}$ \\
\hline $\begin{array}{c}\text { Learning value of } \\
\text { the escape room }\end{array}$ & $8 \%$ & $54 \%$ & $38 \%$ & 4.13 \\
\hline $\begin{array}{c}\text { More or less } \\
\text { valuable than other } \\
\text { learning methods }\end{array}$ & $17 \%$ & $25 \%$ & $58 \%$ & 3.83 \\
\hline $\begin{array}{c}\text { Minimal feedback } \\
\text { method }\end{array}$ & $15 \%$ & $77 \%$ & $8 \%$ & 3.35 \\
\hline
\end{tabular}

Below are some student comments on the escape room activity: 


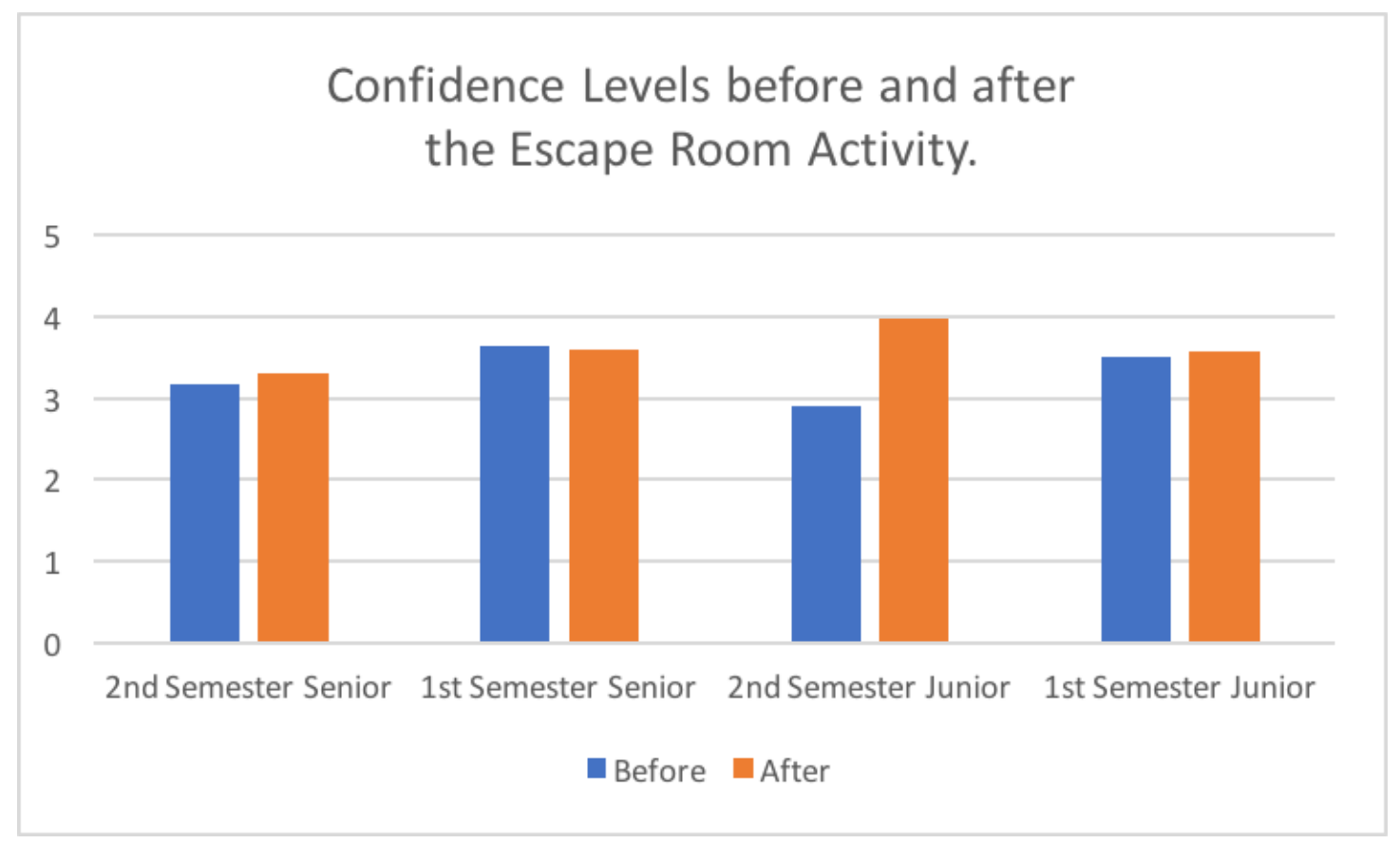

Figure 6: Self-Reported Student Confidence Levels of Fundamental Principles of Engineering Before and After the Escape Room Activity.

- "It was challenging and fun. It was scary. I would have liked to learn what I was missing from an instructor. Clearer instructions. It was inventive and fun."

- "New, different, put a little pressure on us. I have further identified \& verified strengths vs. weaknesses. Nice job, Faculty."

- "Made learning fun, exciting, and highly competitive. Makes you think on your feet. Highly focused. Would be fun to try again."

- "Engaging and challenging. Feedback was key and present. More feedback when people get things wrong."

- "Fun way to start studying for fundamental principles. I don't know if I learned anything new but I was able to recall."

- "Should not be random choice or have prizes. I got all the easy describe components and won with little learning value. Its too random."

\section{Faculty Reflections}

Another form of evaluation is formal faculty reflection. The two authors who have implemented gamification in their courses during the Fall 2017 semester each wrote extensively on their perception of student learning and engagement. This approach fits into the continuous improvement model of the program, where faculty meets together each semester to discuss implementation plans for improvement. 
One co-author's reflection: The motivation for introducing online gamification activities in the classroom environment is to increase student engagement especially with the non-electrical engineering students in the program who are required to take six electrical engineering upper-division courses. I mainly used the online gamification tools to gauge a student's learning with a particular concept quickly. I tried to be strategic by using a tool, of either Plickers or Quizlet, for each topic covered and Kahoot once for the end of the course review. Initially, there is some preparation work to ensure the questions and answers are relevant to the material taught and at the appropriate level to test a student's prior understanding. After a set of questions/answers has been developed for a particular topic, it becomes easy to implement and use in later semesters for the same course.

The students were very receptive to this form of assessment as it allowed them to "fail" in a safe environment with real-time feedback. The in-class observations matched the self-reported student feedback with the majority of students highly engaged and motivated during the activities. One observation is those students who took extra time to read the questions and think longer before answering usually got it correct compared with those who just guessed without taking the time to think. Another observation is there is some discussion among students who are sitting next to one another about which is the correct answer but each student still has the autonomy to pick their own answer, and they will often disregard their classmate's comments when choosing an answer. Some students complain that they don't like having their wrong answer up on the screen for everyone in the class to see. However, these same students tend to be highly motivated to study hard and do more preparation outside of the class time compared to students who don't care how they appear to their classmates. As an instructor after each gamification activity, I can see the type of questions and content that students commonly struggle with so I can immediately adapt my teaching material for the next class to address these areas. It also reaches out to many different learning types as everyone is equally participating, so the more passive students are more engaged with their peers and the instructor.

One area for improvement is to find a balance between stopping every instance to discuss the problem for the few confused students versus many students who already grasp the concept. When more than half of the students chose the incorrect answer, I will stop to discuss the reasoning behind the correct answer. Another method that seemed to work well is to get a student who got the question right to explain it to the students who got it wrong. The student who got it correctly benefits from having to verbalize their reasoning which further promotes peer to peer learning.

Another co-author reflects: I found the addition of gamification tools to my learning conversations to be refreshing and satisfying. The three online games, Plickers, Quizlet, and Kahoot, are an easy way to add some fun and challenge to the classroom. I used Kahoot most often because it is easy to create the "quizzes" and is extremely easy to carry out. Some students reported using Kahoot in their high school classes, so there was virtually no training needed on how to use the game in class. All three online games require some initial faculty preparation work. While there are many question sets already created, I found that I always had to adapt them significantly to make it best fit my particular use for that next class meeting. Often, I would skip trying to find an existing question set, and instead just type in some text-book provided quiz questions and answers in a new quiz. Setting up one of these online games takes approximately 
30 - 45 minutes each; they can be re-used in future semesters, so the long-term time commitment is low. I used the online games as practice quizzes and did not keep track of individual student scores, to make this a low-key method to practice interleaved spaced retrieval activity. The amount of social learning when the correct answer is displayed is high. Students immediately react out loud when the correct answer is revealed, whether they got it right or not, and explanations of both are immediately heard. Rarely did I have to review the reasoning behind the correct answer, as the students would discuss this themselves, without my prompting, thus unleashing the power of peer-to-peer learning. Some of the defenses put forth by students when they get an answer wrong, and it is publicly displayed are worth addressing. I allow students to work in self-selected pairs so that the identity of "who got it wrong" is somewhat masked. I still find that wrong answers are beneficial for the students and the instructor alike, as that uncovers challenging or misunderstood topics. Students seem to learn a great deal from playing these games, both from the correct and the incorrect answers. The experience is fun, motivating, and positive addition to the classroom learning activities.

\section{Conclusions and Future Work}

At Iron Range Engineering, both authors will continue to use these games due to their favorable benefit/cost ratio. After a brief initial overview of these games from one of our university's instructional designers, we found preparation and implementation time to be relatively short and easy. Once a Quizlet, Plickers, Kahoot, or IF-AT game is created, it can be re-used with future groups of students with no additional instructor-preparation time. As a result of using these techniques, we see the benefits of peer to peer learning, active learning, and social learning to be high. The games facilitate more student interaction, so the instructor doesn't talk too much. We want the students to talk more and be engaged more, and gamification helps with managing that. Student comments indicate that they value this type of learning activity and find it enjoyable, engaging, and an effective way to retrieve and practice content from the readings and other resources. The IF-AT cards are handy to use as a beginning of semester icebreaker, as well as an in-class assessment and will continue to be used once or twice a semester. We plan to hold the Escape Room activity once each semester, making minor modifications each time to keep it original for each occurrence.

We recognize the possibility of the long-term decline in adaptability to diverse learning opportunities such as open-ended engineering problems. As such gamification is not a replacement for learning methods; we used gamification in approximately $20 \%$ of the in-class activities. Further research into this is recommended, so educators better understand the consequences of new educational technologies and practices.

Our next steps include ways that we can be more strategic on constructively aligning the gaming learning activities with specific learning outcomes and analyzing the results. For long-term assessment, we plan to compare students' final oral exam scores from non-game to game course sections and to track overall competency scores over time. We also plan to keep close track of individual homework assignment grades that were tied to in-class gaming learning activities to assess their effectiveness. Students are expected to apply learning from technical competencies in their semester-long design projects, so over time, we will evaluate the effect of using gamification 
in technical courses on long-term retention and use of concepts in their project work in later semesters. We expect the impact of gamification in technical courses to have a positive impact on our program. After implementing these learning games into several classes in one semester, we recommend that other engineering educators consider adopting one or more of these games into their courses as an occasional alternative to lecture.

\section{Acknowledgments}

We gratefully acknowledge the support, guidance, and engagement of our faculty colleagues, students as well as our National Advisory Board Members.

\section{References}

[1] K. Kapp, "The Gamification of Learning and Instruction: game-based methods and strategies for training and education", Pfeiffer, 2012.

[2] K. Kapp, L. Blair and R. Mesch, "The Gamification of Learning and Instruction: Fieldbook", Wiley, 2014.

[3] J. Gee, "What video games have to teach us about learning and literacy", Palgrave Macmillan, 2003.

[4] K. Salen and E. Zimmerman, "Rules of play: Game design fundamentals". The MIT Press, 2003.

[5] TED Talks, "Gabe Zichermann: The Future of Creativity and Innovation is Gamification," 2014 [Online]. Available: https://www.youtube.com/watch?v=ZZvRw71Slew. [Accessed: Jan 30, 2018].

[6] P. Cutri, L. Marim, J. Cordeiro, H. Gil,and C. Guerald, "Kahoot, A New and Cheap Way to Get Classroom-Response Instead of Using Clickers", in Proceedings of ASEE Annual Conference and Expo, 2016.

[7] P. Tan and J. Saucerman, "Enhancing Learning and Engagement through Gamification of Student Response Systems", in Proceedings of ASEE Annual Conference and Expo, 2017.

[8] Z. Mahmud, P. Weber, and J. Moening, "Gamification of Engineering Courses", in Proceedings of ASEE Annual Conference and Expo, 2017.

[9] Y. Fu and P. Clarke, "Gamification-Based Cyber-Enabled Learning Environment of Software Testing”, in Proceedings of ASEE Annual Conference and Expo, 2016.

[10] Aalborg University, Denmark, 'Problem based Project Work at Aalborg University," [Online]. Available: http://www.en.aau.dk/education/problem-based-learning/project-work/. [Accessed: Jan 30, 2018]. 
[11] R. Ulseth and B. Johnson, "Iron Range Engineering PBL Experience", in PAEE 2015 International Symposium on Project Approaches in Engineering Education, International Joint Conference on the Learner in Engineering Education, Donostia-San Sebastian, Spain, 6-9 July 2015.

[12] 'Plickers," [Online]. Available: https://plickers.com/. [Accessed: Jan 30, 2018].

[13] "Kahoot," [Online]. Available: https://kahoot.com/. [Accessed: Jan 30, 2018].

[14] "Quizlet," [Online]. Available: https://quizlet.com/. [Accessed: Jan 30, 2018].

[15] 'Immediate Feedback Assessment Technique (IF-AT)," [Online]. Available: http://www.epsteineducation.com/home/about/. [Accessed: Jan 30, 2018].

[16] Science Education Resource Center, Carleton College, "What is Gallery Walk?," [Online]. Available: http://serc.carleton.edu/introgeo/gallerywalk/what.html. [Accessed: Jan 30, 2018]. 